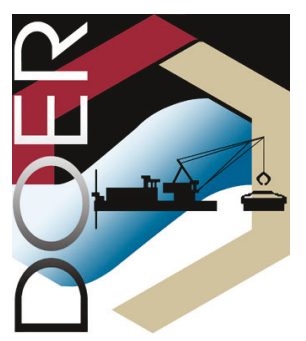

ERDC/TN DOER-R26

August 2018

\title{
Toxicity Reduction (and Identification) for Dredging Evaluations: Methods for Whole Sediment Elutriate Bioassays
}

\author{
by Nicolas L. Melby', Alan J. Kennedy', J. Daniel Farrar', \\ Anthony J. Bednar', David W. Moore', and Wade Lehmann'
}

PURPOSE: Physical, chemical, and toxicological characterization of sediment may be required to evaluate dredged material (DM) under the Clean Water Act (CWA) or Marine Protection Research and Sanctuaries Act (MPRSA). When DM evaluations indicate potential for biological effects, it is useful to identify the likely causes of those effects to better inform test interpretation and/or management decisions (USEPA/USACE, 1991). For example, when a non-persistent substance, such as ammonia, is present at elevated levels that are sufficient to alone cause a toxicological effect in laboratory bioassays, it is logical to employ methods to reduce ammonia levels prior to conducting the bioassay to allow toxicological assessment for more persistent contaminants of concern. The primary objective of this Technical Note (TN) was to disseminate methods for conducting toxicity reduction/identification evaluations (TRE/TIE) to be used in select dredging evaluations. While previous documents have discussed the utility of TRE/TIE information for dredging management decisions, this TN provides more specific guidance. In practice, TREs for ammonia in elutriate toxicity tests may be most common and applicable. TRE methods serve as supplementary testing to standard whole sediment and sediment elutriate bioassays in which significant reductions in survival (or other endpoints) are observed, but the primary cause is unknown or suspected to be ammonia, hydrogen sulfide, or other non-contaminant related factors. Through sediment and elutriate manipulations, these methods can generate lines of evidence that a certain chemical class (or specific chemical compound or element when coupled with chemistry data) is primarily responsible for observed biological effects. The drivers of the biological effects may be narrowed to typical contaminants/classes; organic compounds, metals 3 , ammonia, and/or sulfides (Ankley et al. 1992; Kreitinger et al. 2017). Application of the methods described herein is beneficial to align the type of data generated between different dredging projects, thus allowing greater consistency of robust, scientific data that feed management decisions.

BACKGROUND: Whole sediment and sediment elutriate bioassays are used in dredging evaluations to assess the potential environmental and ecological impacts of the open-water placement of DM. Detailed backgrounds on DM evaluations and the purpose of different aquatic ecotoxicology bioassays and issues encountered were previously described in Postma et al (2002) and Kennedy et al. $(2009,2015)$. The results of toxicity bioassays may indicate statistically significant reduction in survival (or other test endpoints), and the cause of that toxicity may be, at least partially, project specific contaminants of concern $(\mathrm{CoC})$, non-persistent contaminant effects (e.g., ammonia, sulfides), physical effects (e.g., grain size) or nutritional effects (Postma et al.

\footnotetext{
${ }_{1}^{1}$ Environmental Laboratory, U.S. Army Corps of Engineers, 3909 Halls Ferry Road, Vicksburg, MS 39180-6199.

${ }^{2}$ Marine Regulatory and Wetlands Enforcement Section, U.S. Environmental Protection Agency - Region 4, Atlanta, GA.

${ }^{3}$ Available resins are specific for cationic metals
} 


\section{ERDC/TN DOER-R26}

August 2018

2002). In some cases it may be unclear what the underlying cause of significant reductions in toxicity test endpoints is, and whether the cause is "toxicity due to specific contaminants." Scientists from the U.S. Environmental Protection Agency (USEPA), Office of Research and Development (Ankley et al. 1992) discussed that a bioassay resulting in a statistically significant endpoint reduction is not necessarily sufficient as the sole source of information to make a dredging management decision. Specific examples were provided, including the presence of toxic levels of ammonia or hydrogen sulfides, which are typically sourced from natural microbial processes, and may be of lower management concern relative to persistent contaminants. Therefore, knowledge of the cause of the effects observed in bioassays may be informative to management decisions, such as when the effects are due to CoCs versus ammonia, for which alternative safety factors, hereafter referred to as application factors (AFs), may be used (Kennedy et al. 2015). Current regulations (40 CFR 227.27) allow for the use of scientifically defensible, alternative AFs for determining the Limiting Permissible Concentration (LPC). The LPC is considered an acceptable concentration for DM placement and discharge. As previously described, ammonia is often present in DM at levels that are toxic to test organisms in the laboratory (Sims et al. 1995; Kennedy et al. 2015; Kennedy et al. 2017), but the effect in the field is less clear, and ammonia and sulfides are not necessarily project specific CoCs in management decisions.

For whole sediment bioassays, since ammonia is naturally occurring and non-persistent, it is not typically considered a $\mathrm{CoC}$, and in common laboratory practice can be reduced to nontoxic levels in order to better characterize the potential toxicity of persistent CoCs (USEPA/USACE 1991, 1994, 1998, 2008). Laboratories should measure ammonia in sediment prior to setting up sediment toxicity bioassays, and purge the sediments of ammonia according to guidance through a series of water exchanges (USEPA/USACE 1991, 1994, 1998, 2008) as necessary. For sediment toxicity tests, available TRE/TIE methods are described in detail, both generally (USEPA 2007), and in a dredging evaluation context (Kreitinger et al. 2017).

For water column assessments using sediment elutriate toxicity tests, ammonia may not be of concern. However, if ammonia is released from sediments into water during elutriation at sufficient concentrations to cause toxicity in the bioassay (and it is not identified as the cause), it could be unintentionally managed like a persistent $\mathrm{CoC}$. If ammonia is identified as a cause for the toxicity, it may be considered in certain projects, in regard to how much dilution is required at the DM placement site to meet compliance requirements (e.g., ammonia concentrations are compared to ammonia water quality criteria after allowing for mixing). When necessary, ammonia can be reduced via manipulation of the sediment and/or elutriates to determine if it is the probable cause of toxicity. Similarly, elutriate waters can be manipulated to reduce the toxicity of organic compounds and metals, further delimiting the possible sources of toxicity. Laboratories should measure ammonia, either in sediment pore water to provide some awareness if high ammonia concentrations in elutriate waters may be expected, or make preliminary elutriates prior to bioassays to acquire a more accurate account of ammonia concentrations to be encountered, and compare those levels to species specific ammonia thresholds (Kennedy et al. 2015). As an additional line of evidence, laboratories may conduct reference toxicity tests for each applicable test species using ammonia (e.g., ammonium chloride).

Ankley et al. (1992) described leveraging of USEPA effluent discharge TIE guidance (U.S. EPA 1991) for elutriate toxicity testing, and listed several treatments for providing lines of evidence 
for ammonia and sulfides toxicity, including zeolite treatment and graduated $\mathrm{pH}$ tests. The graduated $\mathrm{pH}$ testing is particularly useful, since a decrease in $\mathrm{pH}$ will reduce the fraction of toxic un-ionized ammonia concentrations, but increase the relative toxicity of sulfides (as well as increase metals bioavailability). However, an increase in $\mathrm{pH}$ will increase the toxicity of ammonia (by increasing the un-ionized ammonia fraction), but decrease the relative toxicity of sulfides and metals. Taken holistically, this multiple treatment approach can supply lines of evidence to inform management decisions based upon robust science. While the focus of Ankley et al. (1992) was primarily for freshwater testing, some of these methods can also be applied to marine testing evaluations. There may be some limitations to these methods in marine systems, such as reduced zeolite efficacy for removing ammonia (Burgess et al. 2004; Ho and Burgess 2008) and greater difficulty maintaining stable $\mathrm{pH}$ values during testing. However, these methods may allow for sufficient reduction of un-ionized ammonia to reduce or eliminate ammonia toxicity in the bioassays, if successfully reduced below known ammonia toxicity thresholds, to provide adequate evidence of ammonia induced toxicity.

METHODS: It is important to apply multiple lines of scientific evidence when making DM management decisions, following current guidance, when making an overall determination if sediment placement poses a risk to the environment. A generalized approach for determining multiple lines of evidence for an ammonia TRE/TIE is provided in Figure 1. The standard elutriate toxicity test (with no modifications) must be conducted to determine the potential baseline toxicity of the DM. It may be advantageous to measure ammonia concentrations in the elutriate water and/or sediment porewater to gain an initial understanding of whether or not ammonia may be expected to cause an impact on the test organism (Table 1). With this information, the decision can be made on the following: (1) wait to determine if toxicity occurs in the standard elutriate test and weigh the benefits of performing a TRE/TIE to the project, or (2) conduct the standard elutriate test and TRE/TIE simultaneously to save time and reduce laboratory mobilization and logistics. If there is concern that ammonia may contribute to toxicity in a sediment elutriate, the sediment may be pre-purged of ammonia by water exchanges (USEPA 1994; USEPA/USACE 1998), or the unpurged sediment can be used to prepare elutriates which are subjected to various treatments (Table 2). For example, elutriates created with unmodified (unpurged) sediment are used for zeolite-treated and $\mathrm{pH}$-adjusted manipulations, while the purged sediment (if applicable), may be used to create elutriates that are treated to determine the likely presence of other potential CoCs, an analysis that would be uninformative if toxic concentrations of ammonia are not first removed. These treatments, along with the rationale for their use, are presented in Table 2. A general photograph of what elutriate manipulations may look like is provided in Figure 2.

As previously discussed, the most common practice may be to reduce ammonia (and perhaps sulfide) levels in a TRE to determine if ammonia was the sole cause of toxicity. It may be less common to perform a full TIE for specific chemical classes beyond ammonia since there is no clarity on how this information flow may impact a regulatory or management decision. To save cost, the utility of a full TIE specific to chemical classes other than ammonia can be determined on a case specific basis by DM managers. 


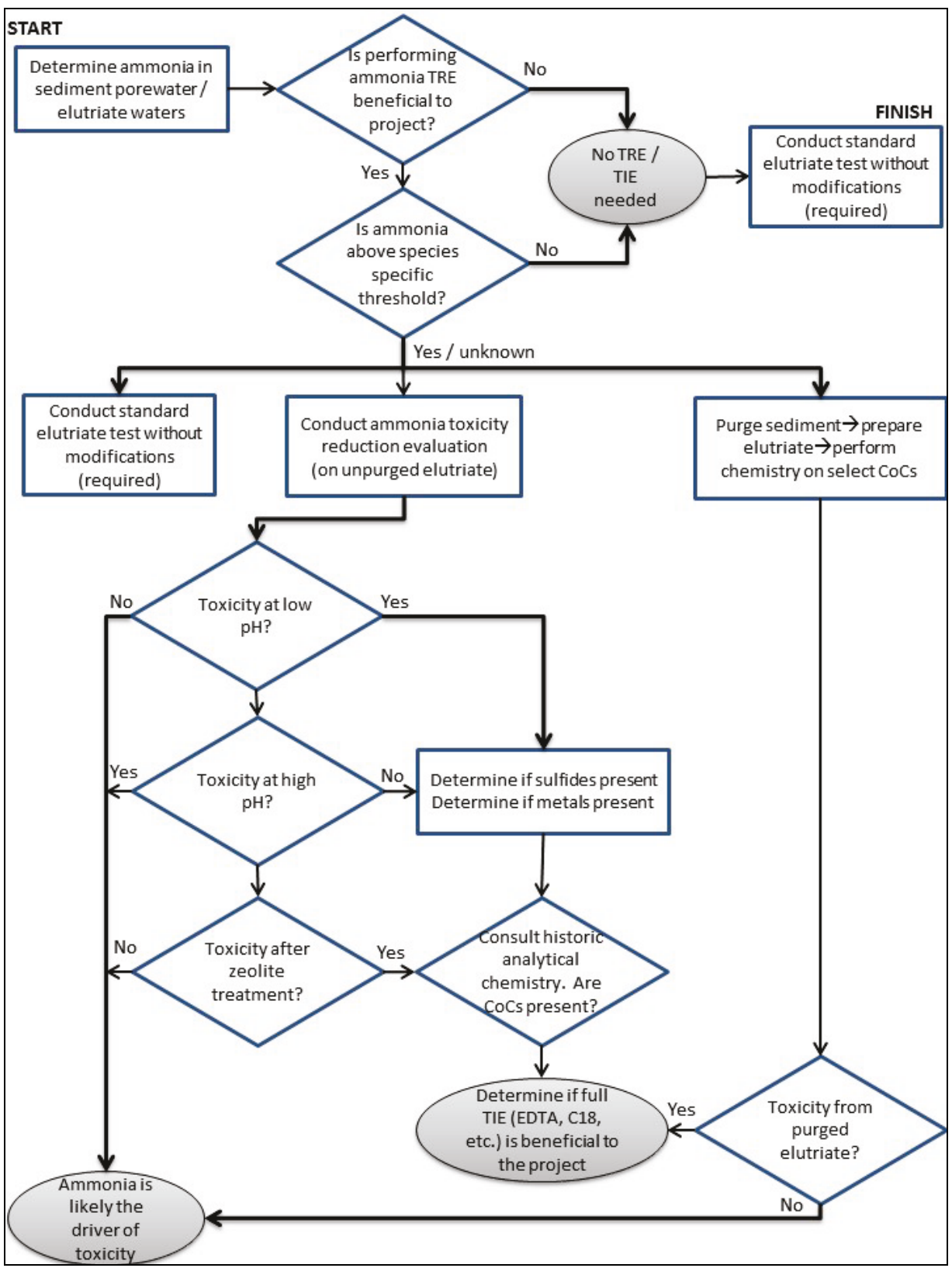

Figure 1. Flow chart providing general guidance on when the conduct of an ammonia toxicity reduction evaluation (TRE) may be of benefit to a dredging evaluation project. It is important to consider if understanding the cause of toxicity will have potential to inform or alter a decision or impact overall project cost. Multiple lines of evidence (graduated $\mathrm{pH}$ tests, zeolite treatments, purged elutriate) are provided below for determining if ammonia is the driver of toxicity. According to MPRSA, the standard elutriate test (without modification) must be performed regardless of the decision for conduction an ammonia TRE. 
Table 1. Example water / pore water ammonia thresholds for common test species. These values are for guidance only and alternative project or testing laboratory specific values may supersede these values. Values in panel A are from literature reported no observable effect concentrations (NOECs) or low observable effects concentrations (EC5, EC10). Values in panel B were derived from testing conducted by NewFields, Environ, and EcoAnalysts, based upon means (and minimum/maximum ranges of NOECs).

\begin{tabular}{|c|c|c|c|}
\hline \multicolumn{3}{|c|}{ A. } \\
\hline Organism type & Test organism & $\begin{array}{c}\text { No or low effect value } \\
\text { (mg/L un-ionized } \\
\text { ammonia) }\end{array}$ & Reference \\
\hline Fish & Menidia beryllina & 0.9 & Boardman et al. 2004; Li \\
\hline Invertebrate & Americamysis bahia & 0.2 & Boardman et al. 2004 \\
\hline Zooplankton & Mytilus spp. & 0.1 & Kennedy et al. 2017 \\
\hline Zooplankton & Arbacia spp. & 0.05 & Carr et al. 1996a,b \\
\hline
\end{tabular}

B.

\begin{tabular}{|c|c|c|c|}
\hline Organism type & Test organism & $\begin{array}{c}\text { Average no observable } \\
\text { effect concentration } \\
\text { (mg/L un-ionized } \\
\text { ammonia) }\end{array}$ & $\begin{array}{c}\text { Range in no } \\
\text { observable effect } \\
\text { concentrations (mg/L } \\
\text { un-ionized ammonia) }\end{array}$ \\
\hline Invertebrate & Americamysis bahia & 0.50 & $(0.35-0.70)$ \\
\hline Vertebrate & Menidia beryllina & 0.60 & $(0.23-1.6)$ \\
\hline Bivalve & Crassostrea gigas & 0.10 & $(0.04-0.16)$ \\
\hline Bivalve & Mytilus edulis & 0.06 & $(0.02-0.16)$ \\
\hline Echinoid & Dendraster excentricus & 0.04 & $(0.02-0.09)$ \\
\hline Echinoid & $\begin{array}{c}\text { Strongylocentrotus } \\
\text { purpuratus }\end{array}$ & 0.03 & $(<0.01-0.10)$ \\
\hline
\end{tabular}




\section{Table 2. Toxicity reduction methods for elutriate waters.}

\section{Treatment of}

Sediment Prior

to Elutriate

Preparation

\begin{tabular}{|c|c|c|c|}
\hline Preparatio & & & \\
\hline None & None & $\begin{array}{l}\text { Establishes baseline } \\
\text { toxicity }\end{array}$ & $\begin{array}{c}\text { Does not provide } \\
\text { information of cause of } \\
\text { toxicity }\end{array}$ \\
\hline None & Adjusting to lower pH & $\begin{array}{l}\text { Reduces toxic un-ionized } \\
\text { ammonia fraction. } \\
\text { Increases toxic fraction of } \\
\text { sulfides and bioavailable } \\
\text { fraction of metals (if } \\
\text { present). }\end{array}$ & $\begin{array}{c}\text { May be difficult to maintain } \\
\text { stable pH. System cannot be } \\
\text { aerated. }\end{array}$ \\
\hline None & Adjusting to higher pH & $\begin{array}{l}\text { Increases toxic un-ionized } \\
\text { ammonia fraction. } \\
\text { Decreases toxic fraction of } \\
\text { sulfides and bioavailable } \\
\text { fraction of metals (if } \\
\text { present). }\end{array}$ & $\begin{array}{c}\text { May be difficult to maintain } \\
\text { stable } \mathrm{pH} \text {. System cannot be } \\
\text { aerated. }\end{array}$ \\
\hline None & Zeolite column & $\begin{array}{l}\text { Directly removes (or } \\
\text { reduces) ammonia }\end{array}$ & $\begin{array}{c}\text { May also reduce some } \\
\text { metals concentrations. May } \\
\text { have lower efficacy in } \\
\text { marine water. }\end{array}$ \\
\hline Purged $^{1}$ & None & $\begin{array}{l}\text { Reduces ammonia in the } \\
\text { sediment porewater and } \\
\text { thus reduces ammonia } \\
\text { released to the water } \\
\text { during elutriation. Allows } \\
\text { TIE treatments for other } \\
\text { chemical classes when } \\
\text { ammonia is at toxic levels. }\end{array}$ & $\begin{array}{l}\text { May also reduce other CoCs } \\
\text { (Analytical chemistry } \\
\text { required to confirm CoCs not } \\
\text { reduced). } \\
\text { May be difficult to } \\
\text { sufficiently reduce ammonia } \\
\text { below known toxic levels } \\
\text { within holding times for } \\
\text { some test species for } \\
\text { microbially active sediments. }\end{array}$ \\
\hline Purged & $\begin{array}{l}\text { Ethylenediaminetetraacetic } \\
\text { Acid (EDTA) treatment }\end{array}$ & $\begin{array}{l}\text { Binds cationic metals } \\
\text { reducing bioavailable } \\
\text { fraction. Reduced toxicity } \\
\text { suggests cationic metals } \\
\text { contributing to toxicity. }\end{array}$ & $\begin{array}{c}\text { Can be toxic to test } \\
\text { organisms. }\end{array}$ \\
\hline Purged & C18 & $\begin{array}{l}\text { Removes organic } \\
\text { constituents. Reduced } \\
\text { toxicity suggests organics } \\
\text { contributing to toxicity. }\end{array}$ & $\begin{array}{c}\text { Care must be applied to } \\
\text { ensure breakthrough of } \\
\text { organics (or solvent rinse) } \\
\text { does not occur. }\end{array}$ \\
\hline
\end{tabular}

\footnotetext{
${ }^{1}$ May be overlying water exchanges as described in USEPA (1994).
} 


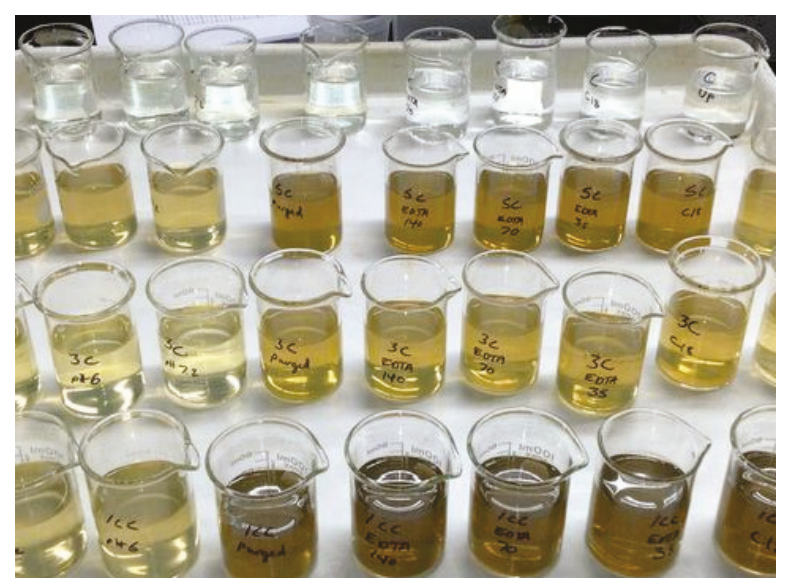

Figure 2. Various TRE/TIE sediment elutriate manipulations including $\mathrm{pH}$, ethylenediaminetetraacetic acid (EDTA), and C18 treatments.

Elutriate manipulations for unpurged elutriates. The following manipulations are intended for elutriates prepared from unmodified (unpurged) sediment. While a zeolite column may be used to reduce ammonia concentrations, it may also reduce concentrations of some metals (Burgess et al. 2003; Kesraoui-Ouki et al. 1994; Anderson, 2000). This may be addressed by moderate $\mathrm{pH}$ reductions (reducing $\mathrm{pH}$ between 6.5 and 7.2), this reduces the more toxic unionized ammonia fraction and, in theory, reduces the bioavailability of most metals. Carefully conducted, moderate $\mathrm{pH}$ modifications are acceptable and useful for elutriate toxicity assessments. However, while drastic increases to $\mathrm{pH}$ values above ten, coupled with aggressive aeration to purge ammonia from the elutriate water has been previously discussed (Ankley et al. 1992) and applied in testing laboratories, this approach generally should not be employed due to potentially irreversible changes in metals speciation. The metals may not go back into solution following a return to circum-neutral $\mathrm{pH}$. If the latter treatment is performed, the results should be interpreted with caution.

Graduated $\mathrm{pH}$ treatments. To execute graduated $\mathrm{pH}$ treatments, place the required volume of freshly prepared elutriate water (prepared with unmodified sediment) into a glass vessel. Mix the water via slow magnetic stirring to avoid formation of a liquid vortex, this may reduce ammonia concentrations (Figure 3). In add $\mathrm{pH}$ adjustments, the minimum amount of acid/base should be used, and any increase in conductivity or salinity should be carefully monitored and documented. Slowly add small amounts of reagent grade hydrochloric acid (1.0, 0.1, and $0.01 \mathrm{~N}$ ) to reduce the $\mathrm{pH}$ of the elutriate water to 6.5 and/or 7.2 (two separate treatments). Record the exact amount of acid used, and monitor the $\mathrm{pH}$ continuously during this process. If increasing the $\mathrm{pH}$ is necessary (i.e., there is question about sulfides toxicity), use 1.0, 0.1 , and $0.01 \mathrm{~N}$ reagent grade sodium hydroxide. If increasing $\mathrm{pH}$, it should be understood that metals availability may be impacted and resulting interpretation should reflect that. After reaching the desired $\mathrm{pH}$, check the $\mathrm{pH}$ every thirty minutes until stability is maintained for a two-hour period. If test methods and sample holding times allow, the water will ideally be equilibrated overnight and adjusted the next day (if needed) before organisms are introduced to ensure stability in the desired $\mathrm{pH}$ value. Once elutriate water has reached equilibrium, gently pour it into test vessels and cover the 
vessels, minimizing headspace to reduce $\mathrm{pH}$ fluctuation. These test treatments cannot be aerated since aeration will increase the $\mathrm{pH}$, therefore, caution should be applied when test waters have high BOD (biological oxygen demand). The same procedure should be followed using control water in order to produce the $\mathrm{pH}$ control.

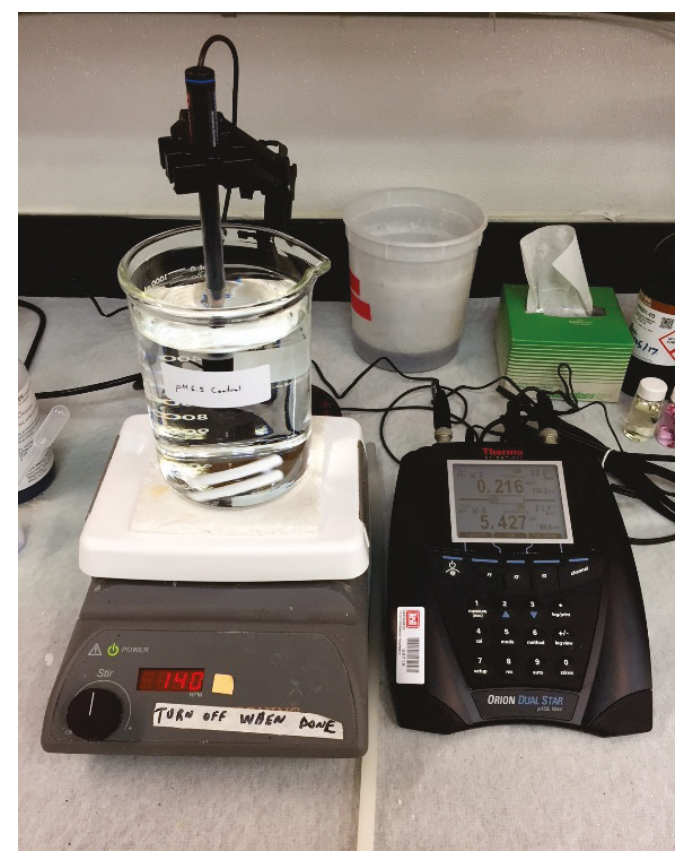

Figure 3. Photograph of elutriate $\mathrm{pH}$ adjustment on magnetic stir plate.

Zeolite. A zeolite column can be used to reduce ammonia concentrations, however, it may also reduce the concentrations of some metals, and it can be less effective in water of high ionic strength (i.e., marine waters) (USEPA 1991; Burgess et al. 2003, 2004). If this is of concern, metal measurements before and after passage through the column may be informative. Modifications to the $\mathrm{pH}$ of elutriate waters may also be used to reduce ammonia toxicity. For example, lowering the $\mathrm{pH}$ of the elutriate (typically between 6.5 and 7.2) increases the ionized fraction and decreases the more toxic un-ionized fraction of ammonia.

A column with openings at each end is used to contain the zeolite (such as SIR-600 resin (ResinTech Inc., West Berlin, NJ, or similar product)). Fit the column with a mesh screen covering the bottom opening in order to keep the substrate in place but also allow the liquid to pass through. For practical purposes the bottom opening should be approximately $1 / 4$ inch in diameter. First, rinse the zeolite with clean water (control, lab water, natural water) until the rinseate runs clear of small particles. Next, fill the column with rinsed zeolite, and then mount it so that the water being treated can pass through the column and into a container or beaker (Figure 4). A ring stand with an attached separatory funnel and claw may be used to hold the elutriate funnel and zeolite column. Slowly drip elutriate water (made with unmodified (unpurged) sediment) through the column (e.g., five drops per second), and retain the treated water. Use separate zeolite columns for each individual treatment, including a zeolite control, which will consist of the same water used for the standard control. 


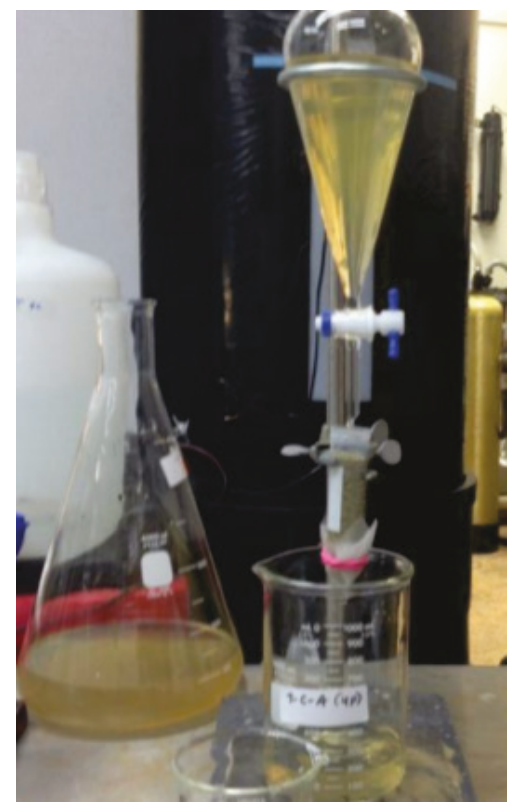

Figure 4. Example set-up of zeolite column.

Purging sediment, prior to elutriate preparation. Sediments to be used in whole sediment and sediment elutriate bioassays can be purged via the facilitated exchange of sediment porewater containing high levels of ammonia with an overlying water source that is free of ammonia. This is conducted prior to testing to bring ammonia concentrations down to non-toxic levels, however, it may be difficult to fully purge microbially active sediments below particularly low test species thresholds for ammonia (Table 1). Purging is routinely performed prior to organism addition in marine sediment toxicity tests by methods leveraged from standard guidance (USEPA 1994; USEPA/USACE 1998). To begin the purging process, a layer $(2-3 \mathrm{~cm})$ of sediment is added to an appropriate container, and the container is marked with a reference line at the sediment level. At least $2-3 \mathrm{~cm}$ sediment depth is recommended to prevent excessive metal oxidation and/or loss. However, this layer should not be too thick, or ammonia purging will be slowed dramatically (possibly beyond holding times). The sediment is then slowly covered with the overlying water specific to the applicable bioassay test method, as often performed for whole sediment toxicity bioassays (USEPA 1994; USEPA/USACE 1998). Several extra replicate containers should be set up to allow intermediate measurements to monitor ammonia reductions in pore water, since sampling is destructive. These measurements may be performed by removing the overlying water and sampling sediment (e.g., $50 \mathrm{~mL}$ ) into a centrifuge tube, and centrifuging the sample to extract the porewater for ammonia-N measurements. During purging, the overlying water should be gently aerated to facilitate ammonia exchange between phases, and up to six water exchanges (70\%) should be performed daily until the porewater ammonia measurement is below the test method specific target level (Kennedy et al 2015, Table 1). When replacing overlying water, a turbulence reducer should be used to prevent re-suspension of the sediment at the water interface. After purging is complete, overlying water is removed to the reference line marked on the container. Since purging can reduce concentrations of some CoCs, analytical chemistry samples should be collected for both the purged and unpurged sediment and analyzed for CoCs (most notably soluble metals and volatile compounds). 
The purged sediment manipulate can be tested as a standalone treatment, in which the purged sediment is used to make a standard elutriate. The modified sediment is directly tested in bioassays to determine if toxicity is removed or reduced.

Purging sediment, manipulations. The following manipulations, if deemed necessary, are intended for sediment that was purged of ammonia prior to elutriate preparation. Alternatively, if ammonia is low and metals or organics are suspected to be potential causes of toxicity, these manipulations may be applied to an unpurged sediment elutriate. In either case, Ethylenediaminetetraacetic acid (EDTA) and C18 treatments can reduce the bioavailability and toxicity of cationic metals and organics, respectively, and their applications and limitations are further described below.

Ethylenediaminetetraacetic acid (EDTA). In the case that metals may be contributing to toxicity, EDTA can be added to elutriate waters to reduce cationic metal toxicity. EDTA acts as a chelating ligand to bind cationic metals in solution, forming complexes that are less toxic than the free metals. Adding EDTA to elutriate waters will have varying efficacy based on factors such as the types and amounts of metals and other ligands present, EDTA's binding affinity for dissolved metals, dissolved metals' binding affinity for test organism tissue, and $\mathrm{pH}$ (USEPA 1991). If toxic levels of ammonia are present, the sediment may be purged prior to elutriate preparation.

First, prepare an EDTA stock by dissolving EDTA in ultra-pure water (example stock concentration is $1.75 \mathrm{~g}$ EDTA in $100 \mathrm{~mL}$ ultra-pure water). Store the stock in an opaque plastic container until it is ready for use. Three concentrations $(35 \mathrm{mg} / \mathrm{L}, 70 \mathrm{mg} / \mathrm{L}$, and $140 \mathrm{mg} / \mathrm{L}$ EDTA) are then produced for each individual elutriate water (made with purged sediment) and the control by spiking the water with the previously prepared EDTA stock. After spiking, mix the water and allow two hours for equilibration before pouring into test vessels and adding organisms.

C18 treatment. If organic compounds are a concern, they can be removed from elutriate waters by using a peristaltic pump to pass the elutriate waters through silica-based $\mathrm{C} 18$ cartridges, The column will adsorb the potentially toxic organic compounds. Depending on the resin material used and the presence of metals, organic matter, other ligands, etc., metals could also be adsorbed by the $\mathrm{C} 18$, so users should be aware that it is possible for metals to be reduced through the $\mathrm{C} 18$ column. If this is of concern, metal measurements before and after passage through the column may be informative. In bioassays utilizing any of these toxicity ameliorating methods, each modification will be replicated using control water in order to ensure that the manipulations themselves are not sources of significant reductions in survival to test organisms.

Start the treatment by attaching a C18 pack (commercially available from a number of scientific supply vendors) to peristaltic pump tubing (Figure 5). Multiple packs may be connected in tandem if there is concern of contaminant breakthrough. Pass $25 \mathrm{~mL}$ of HPLC grade methanol through the column (to activate the carbon) at a rate not to exceed $10 \mathrm{~mL}$ per minute. Follow the methanol immediately with $50 \mathrm{~mL}$ of ultra-pure water. Without allowing the column to dry, slowly pass elutriate water (made with purged sediment) through the column, discarding the initial 25 to $30 \mathrm{~mL}$ of the sample to pass through the C18 pack. Collect the remainder for use in the bioassay. Replace the $\mathrm{C} 18$ pack when the volume that has been passed through exceeds $650 \mathrm{~mL}$. Retain the filtrate, aerate it for 15 minutes, and pour into test vessels before adding test organisms. 


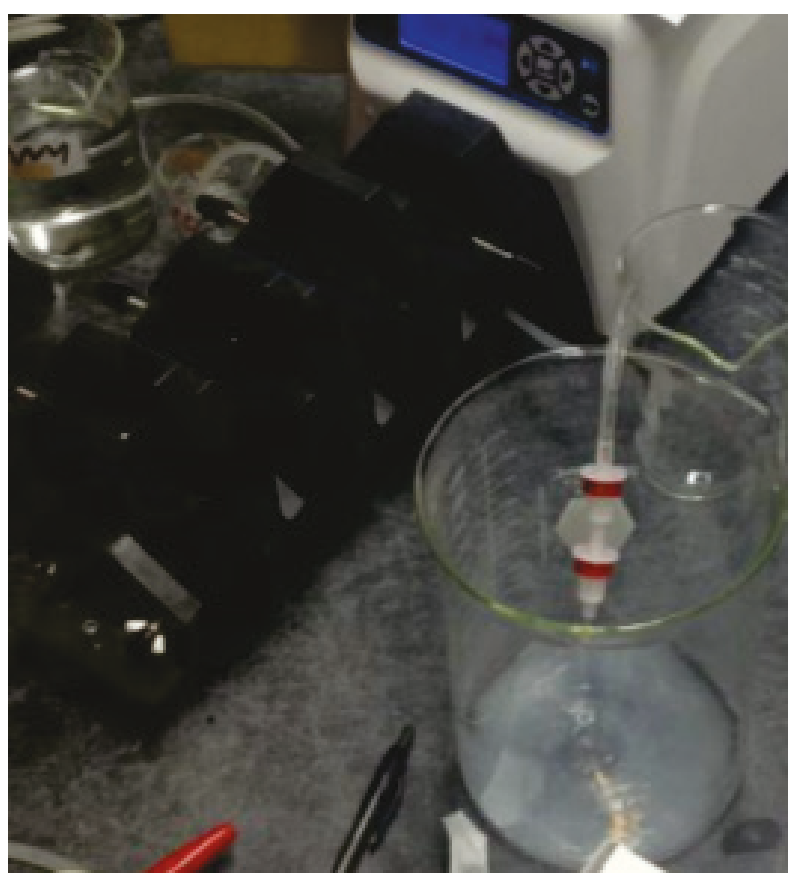

Figure 5. C18 set-up with elutriate water passing through cartridge.

Whole sediment TRE/TIE methods. The need to install sediment TRE/TIE into dredging evaluations to support management decisions using a phased approach was recently discussed by Kreitinger et al. (2017). While those authors provided a preliminary strategy and summarized different treatments, this document further supports that effort by supplying more specific methodology. As stated above for elutriate toxicity testing, the following should be determined: (1) if an ammonia TRE, or (2) if a general contaminant TIE would have benefit in identifying the toxic fraction of project sediments.

If pore water ammonia levels are above species specific thresholds (Table 3), it is generally logical to purge sediment in bioassay test chambers of ammonia according to guidance (USEPA 1994; USEPA/USACE 1991, 1998). This is acceptable since ammonia is not generally considered a contaminant of concern in sediment toxicity testing (Ankley et al. 1992; USEPA 1994; USEPA/USACE 1998) due to its ephemeral nature. This process involves up to twice daily water exchanges (approximately $70 \%$ ) and heavy aeration in the test chambers prior to test initiation until porewater ammonia concentrations are at a species specific threshold (e.g., estuarine/marine amphipods) or $\leq 20 \mathrm{mg} / \mathrm{L}$ for freshwater whole sediment test organisms (USEPA/USACE 1998). Porewater ammonia is also measured at test termination to ensure ammonia concentrations remained low during sediment exposure. Since in most cases, ammonia is addressed at test initiation, it is typically eliminated as a potential cause of toxicity. Therefore, a zeolite treatment would not be needed during a subsequent TRE/TIE. 
Table 3. Example water/pore water ammonia thresholds for common test sediment toxicity test species. Alternative project or testing laboratory specific values may supersede these values. Values in panel B were derived from testing conducted by NewFields, Environ, and EcoAnalysts, based upon means (and minimum/maximum ranges of no observable effects concentrations, or NOECs).

\begin{tabular}{|c|c|c|c||}
\hline Organism type & Test organism & $\begin{array}{c}\text { Average no effect } \\
\text { concentration } \\
\text { (mg/L un-ionized ammonia) }\end{array}$ & $\begin{array}{c}\text { Range in no effect } \\
\text { concentration (mg/L un- } \\
\text { ionized ammonia) }\end{array}$ \\
\hline Amphipod & Leptocheirus plumulosus & 0.95 & $(0.36-2.69)$ \\
\hline Amphipod & Eohaustorius estuarius & 0.86 & $(0.31-1.75)$ \\
\hline Amphipod & Ampelisca abdita & 0.59 & $(0.17-1.14)$ \\
\hline Amphipod & Rhepoxynius abronius & 0.37 & $(0.23-0.57)$ \\
\hline Invertebrate & Americamysis bahia & 0.50 & $(0.35-0.70)$ \\
\hline
\end{tabular}

In some cases when toxicity is observed in sediment toxicity tests, there may be benefit to a dredging project to generate lines of evidence to ascertain the likely contaminant or contaminant class. One clear benefit would be to apply TIE methods when sediment particle size or low organic carbon are suspected to be the cause of organism mortality in sediment toxicity tests. If no sediment manipulation reduced the adverse effect on the test animals, a line of evidence would be provided that the effect is likely not caused by the typical chemical classes (metals, organics, and ammonia). Integration of this result with analytical chemistry would provide multiple lines of evidence for such a conclusion. However, it should be determined whether TIE information may have any impact on a regulatory or management decision provided that toxicity is identified, and the material may be deemed unsuitable for open water placement regardless. TIE information may be useful for planning future projects, delineating future dredging management units, understanding impacts and sources, and engaging stakeholders.

The USEPA has developed testing procedures to help identify causality in sediment toxicity tests (USEPA 2007). The procedures rely upon standard toxicity testing methods that include physical/chemical manipulations of the sample that are designed to elucidate the cause(s) of toxicity. The procedures have been categorized into three similar, but functionally different testing phases. The three phases are as follows: (1) characterize the nature of the toxicity into several classes (e.g., metals, organic compounds, and ammonia), (2) identify the specific toxicants responsible for the observed adverse effects, and (3) confirm the identity of the chemical(s) causing toxicity. The complexity and expense of the procedures increases with each phase. The phases and treatments for sediment TIEs is discussed specifically in the context of DM evaluations by Kreitinger et al (2017).

Phase I TIE evaluation. Due to the complexity and cost associated with a phase II and III evaluation, most dredging TRE/TIE efforts will likely be focused on a phase I evaluation. General guidance for sediment TREs/TIEs is available (U.S. EPA 2007). Sediment contaminants would be identified to one of the three following contaminant classes: (1) organic, (2) metal, or (3) ammonia. To conduct a phase I TRE/TIE, a standard toxicity test, such as a ten-day acute toxicity test, would be conducted using amended sediments. Contaminant bioavailability is 
manipulated by adding amendments to the sediment that specifically bind contaminants from each of the three contaminant classes (i.e., organics, metals, and ammonia) and render the contaminants unavailable to interact with the organism therefore reducing toxicity. In most cases, bulk sediment chemistry can help guide selection of appropriate amendments.

The sediment amendments include activated carbon (organics), SIR-300 cation exchange resin (metals), and SIR-600 zeolite resin (ammonia). An optional treatment is the inclusion of a blend of activated carbon and SIR-300 (organics and metals). The use of a mix helps identify the cause of toxicity where both organics and metals are driving toxicity concurrently. In most cases, powdered or granular activated carbon is used for targeting organics (USEPA 2007). Care should be taken to ensure the test organism can tolerate the particle size of the powdered activated carbon before use. The amendments are added individually to the contaminated sediment. A baseline sediment (unamended) is included, this is used for statistical comparison of amended sediments to determine the level of reduced toxicity. A sand control is also included. The sand control is the contaminated sediment with clean sand added at the highest amendment rate utilized in the activated carbon, SIR-300 and SIR-600 amended sediments. The sand control is used to determine if a dilution effect on toxicity from amendment addition has occurred. Amendment controls, which are performance control sediment with amendments added at the concentration level used in the contaminated sediment, are used to determine if toxicity occurred from exposure to the amendments. Finally, a standard performance control is included for establishing test validity. Individual treatment levels in a phase I TIE of a contaminated sediment are listed in Table 4 below.

Table 4. Typical treatments in a Phase I TRE/TIE on whole sediments.

\begin{tabular}{|cc|}
\hline $\begin{array}{c}\text { Sediment Treatment } \\
\text { Performance Control }\end{array}$ & To evaluate test system performance \\
\hline Baseline & Unamended sediment for comparison to amended sediment \\
\hline Sand Control & To evaluate the dilution effect of amendments on toxicity \\
\hline Carbon Control & To evaluate the influence of the carbon amendment on toxicity \\
\hline SIR-300 Control & To evaluate the influence of SIR-300 amendment on toxicity \\
\hline SIR-600 Control & To evaluate the influence of zeolite amendment on toxicity \\
\hline Carbon amendment & To determine if organics are responsible for toxicity observed \\
\hline SIR-300 amendment & To determine if metals are responsible for toxicity observed \\
\hline SIR-600 amendment (zeolite) & To determine if ammonia is responsible for toxicity observed \\
\hline Blended amendment & To determine if both organics and metals are responsible for \\
(optional) & toxicity observed \\
\hline
\end{tabular}

At test termination, the level of reduced toxicity is determined by statistically comparing the amended sediments to the baseline sediment. The amendment that reduces toxicity is likely binding the contaminant causing the observed toxicity. The Phase I TIE procedure and decision making process is outlined in Kreitenger et al. (2017).

Limitations of a Phase I sediment TRE/TIE. Identifying the source of toxicity to contaminant class is easily accomplished when a sediment is contaminated primarily with a high level of a single contaminant such as PCBs, PAHs, pesticides, or metals. In many cases, there is 
co-occurrence of contaminants at various levels which may result in mixture influenced toxicity. In these cases it becomes more difficult to determine which class of contaminant is the cause of toxicity, since the toxicity of one can mask the toxicity of the other. As described above, one approach for evaluating mixture toxicity is to use a blend of amendments. For example, if chemistry analysis shows high levels of PAHs and metals, then a blend of activated carbon and SIR-300 can be added as a treatment level to determine if PAHs and metals are acting together to produce toxicity.

The presence of unusual toxicants or biological factors, both man-made and naturally occurring, can influence the results of a phase I TIE. There are a number of naturally occurring environmental toxicants in aquatic environments (e.g., organic acids, algal blooms, etc.), though not typically expected, that may result in toxicity to macroinvertebrates, but would not be identified in TIE testing. Although the specific cause of toxicity may not be identified in these cases, it is possible that a phase I TIE could eliminate classes of contaminants as the cause if toxicity is not reduced in the amended sediment for that particular contaminant class.

CONCLUSION: The sediment and elutriate modifications, ammonia purging methods, and TRE/TIE methods described herein, have been proven to be effective at supplementing Tier 3 whole sediment and sediment elutriate bioassays, providing useful lines of evidence suggesting a cause of toxicity. In many cases, ammonia, specifically the un-ionized fraction, can be the main driver of toxicity. Similarly, the phase I procedures for sediment TRE/TIE have been shown to be a good approach for identifying the cause of toxicity to contaminant class or providing supporting evidence that toxicity could be occurring due to a non-contaminant factor.

This DOER Technical Note should be referenced as follows:

Melby, N. L., A. J. Kennedy, J. D. Farrar, A. J. Bednar, D. W. Moore, and W. Lehmann. 2018. Toxicity Reduction (and Identification) for Dredging Evaluations: Methods for Whole Sediment Elutriate Bioassays. ERDC/TN DOERR26. U.S. Army Engineer Research and Development Center, Vicksburg, MS.

\section{REFERENCES}

Anderson, M. A. 2000. "Removal of MTBE and other organic contaminants from water by sorption to high silica zeolites.” Environmental Science and Technology 34(4):725-727. doi: 10.1021/es990390t.

Ankley, T., M. K. Schubauer-Berigan, and R. A. Hoke. 1992. "Use of toxicity identification evaluation techniques to identify dredged material disposal options: A proposed approach.” Environmental Management 16(1): 1-6.

Boardman, G. D., S. M. Starbuck, D. B. Hudgins, X. Li, D. D. Kuhn. 2004. "Toxicity of ammonia to three marine fish and three marine invertebrates." Environmental Toxicology 19(2):134-142.

Burgess, R. M., M. C. Pelletier, K. T. Ho, J. R. Serbst, S. A. Ryba, A. Kuhn, M. M. Perron, P. Raczelowski, and M. G. Cantwell. 2003. "Removal of ammonia toxicity in marine sediment TIEs: a comparison of Ulva lactuca, zeolite and aeration methods." Marine Pollution Bulletin 46(5):607-618.

Burgess, R. M., M. M. Perron, M. G. Cantwell, K. T. Ho, J. R. Serbst, M. C. Pelletier. 2004. "Use of zeolite for removing ammonia and ammonia-caused toxicity in marine toxicity identification evaluations." Archives of Environmental Contamination and Toxicology 47(4):440-447.

Carr, R. C., D. C. Chapman, C. L. Howard, and J. M. Biedenbach. 1996a. "Sediment quality triad assessment survey of the Galveston Bay, Texas system.” Ecotoxicology 5(6):341-364. 
Carr, R. S., D. C. Chapman, B. J. Pressley, J. M. Biedenbach, L. Robertson, L. Boothe, R. Kilada, T. Wade, and P. Montagna. 1996b. "Sediment porewater toxicity assessment studies in the vicinity of offshore oil and gas production platforms in the Gulf of Mexico." Canadian Journal of Fish and Aquatic Science 53: 2618-2628.

Ho, K. T., and R. M. Burgess. 2008. "Marine sediment toxicity identification evaluations (TIEs): history, principles, methods, and future research." In Contaminated Sediments 75-95. Berlin Heidelberg: Springer.

Kennedy, A. J., J. A. Steevens, G. R. Lotufo, J. D. Farrar, M. R. Reiss, R. K. Kropp, J. Doi, and T. S. Bridges. 2009. "A comparison of acute and chronic toxicity methods for marine sediments." Marine Environment Research 68(3):118-127.

Kennedy, A J., G. R. Lotufo, and J. A. Steevens. 2015. "Review of dredged elutriate application factors: relevance to acute-to-chronic protection, contaminant, and endpoint specificity." ERDC/EL TR-15-10. Vicksburg, MS: U.S. Army Engineer Research and Development Center.

Kennedy, A. J., J. H. Lindsay, J. M. Biedenbach, and A. R. Harmon. 2017. "Life stage sensitivity of the marine mussel Mytilus edulis to ammonia." Environmental Toxicology and Chemistry 36(1):89-95.

Kesraoui-Ouki, S., C. R. Cheeseman, R. Perry. 1994. Natural zeolite utilisation in pollution control: a review of applications to metals effluents. Journal of Chemical Technology and Biotechnology 59, 121-126.

Kreitinger, J. P., J. D. Farrar, and G. R. Lotufo. 2017. "Application of Toxicity Identification and Evaluation Procedures for Dredged Material Management." DOER Technical Notes Collection (ERDC TN-DOER-R25). Vicksburg, MS: U.S. Army Engineer Research and Development Center.

Li, X. 1997. "The toxicity of ammonia to Atlantic silverside (Menidia menidia) and ghost shrimp (Palaemonetes pugio).” Virginia Tech: M.S. Thesis.

Postma, J. F., S. de Valk, M. Dubbeldam, J. L. Maas, M. Tonkes, C. A. Schipper, and B. J. Kater. 2002. "Confounding factors in bioassays with freshwater and marine organisms." Ecotoxicology and Environmental Safety 53(2):226-237.

Sims, J. G., and D. W. Moore. 1995. "Risk of Porewater Ammonia Toxicity in Dredged Material Bioassays. Dredging Operations Technical Support (DOTS) Program." Miscellaneous Paper D-95-3. U.S. Army Waterways Experiment Station, Vicksburg, MS.

U.S. Environmental Protection Agency (USEPA).1991. "Methods for Aquatic Toxicity Identification Evaluations: Phase I Toxicity Characterization Procedures" $2^{\text {nd }}$ ed. EPA/600/6-91/003. Washington, DC: U.S. Environmental Protection Agency, Office of Research and Development.

U.S. Environmental Protection Agency/U.S. Army Corps of Engineers (USEPA/USACE). 1991. "Evaluation of dredged material proposed for ocean disposal (ocean testing manual)." EPA 503/8-91/001. Washington, DC: U.S. Environmental Protection Agency.

U.S. Environmental Protection Agency (USEPA). 1994. "Methods for assessing the toxicity of sediment-associated contaminants with estuarine and marine amphipods." EPA/600/R-94/025. Washington, DC: U.S. Environmental Protection Agency.

U.S. Environmental Protection Agency/U.S. Army Corps of Engineers (USEPA/USACE). 1998. "Evaluation of material proposed for discharge to waters of the US - testing manual (inland testing manual)." EPA/823/B98/004. Washington, DC: U.S. Environmental Protection Agency.

U.S. Environmental Protection Agency USEPA. 2007. "Sediment Toxicity Identification Evaluation (TIE) Phases I, II, and III Guidance Document." EPA/600/R-07/080. Washington, DC: U.S. Environmental Protection Agency, Office of Research and Development.

U.S. Environmental Protection Agency/U.S. Army Corps of Engineers (USEPA/USACE). 2008. "Regional implementation manual - requirements and procedures for evaluation of the ocean disposal of dredged material in Southeastern U.S. Atlantic and Gulf Coast Waters (SERIM).” Atlanta, GA: U.S. Environmental Protection Agency Region 4 and U.S. Army Corps of Engineers, South Atlantic Division.

NOTE: The contents of this technical note are not to be used for advertising, publication, or promotional purposes. Citation of trade names does not constitute an official endorsement or approval of the use of such products. 